\title{
Effectiveness of Acceptance and Commitment Therapy on Occupational Stress and Anxiety of Nurses Caring for Patients With COVID-19 in Tehran
}

\author{
Hasan Mosazadeh $^{1 *(\mathbb{D}}$, Aleksandra Błachnio $^{1}{ }^{(\mathbb{D}}$, Bijan Pirnia $^{2,3}$ \\ ${ }^{1}$ Department of Psychology, Kazimierz Wielki University in Bydgoszcz, Poland \\ ${ }^{2}$ Department of Psychology, Faculty of Humanities, University of Science and Culture, Tehran, Iran \\ ${ }^{3}$ Behavioral Sciences Research Center, Shahid Beheshti University of Medical Sciences, Tehran, Iran
}

\begin{abstract}
Background: This research aims to evaluate the impact of acceptance and commitment therapy (ACT) on the occupational stress and the anxiety of nurses.

Methods: This was an experimental study with pre-test post-test design with a control group. We included all nurses caring for patients with COVID-19 in governmental hospitals in Tehran during six months of 2020. Beck's Anxiety Inventory (BAI) and Steinmetz Occupational Stress Questionnaire were used for data collection.

Results: Box's test $(P=0.225)$ showed that the covariance-variance matrices were homogeneous. Levine's test also indicated that the assumption of variance equality was observed. The amounts of ETA square root showed that $66.3 \%$ of the anxiety variance and $51.3 \%$ of the occupational stress variance could be predicted in the posttest through ACT.

Conclusion: The rate of occupational stress and anxiety of the test group significantly decreased compared with the control group after the intervention. Therefore, ACT could decrease the occupational stress and anxiety of nurses and the therapists could use this approach for improving the mental health of nurses.

Keywords: Acceptance and commitment therapy; COVID-19; Occupational stress; Anxiety; Nurse.
\end{abstract}

\author{
*Correspondence to \\ Hasan Mosazadeh \\ Department of Psychology, \\ Kazimierz Wielki University in \\ Bydgoszcz, Poland \\ Tel: +48570473606 \\ Email: htmosazadeh@gmail. \\ com
}

Published online June 30 2021

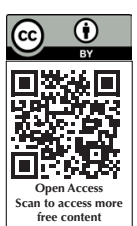

Citation: Mosazadeh H, Błachnio A, Pirnia B. Effectiveness of acceptance and commitment therapy on occupational stress and anxiety of nurses caring for patients with COVID-19 in Tehran. Clin Neurosci J. 2021;8(3):124-128. doi:10.34172/icnj.2021.26.

\section{Introduction}

In late December 2019, a new Coronavirus named the novel coronavirus-2019 (COVID-19) caused a new pandemic from Wuhan throughout China which has caused significant health threats for the general public around the globe. ${ }^{1}$ The COVID-19 epidemic is expanding throughout the world and has infected nearly all countries worldwide, including Iran, by March $2020 .^{2}$ There is no evident antivirus treatment or vaccination for COVID-2019 infections ${ }^{3}$; therefore, the important role of the medical team has become more evident. There is scant data on the clinical features and natural development of the disease in patients with COVID-19. ${ }^{4}$ The threatening context of the pandemic indicates the well-known problem of burnout (exhaustion and fatigue, stress, weakness, and immobility). ${ }^{5}$ Nurses should maintain their psychological health to ensure the quality of care for patients. ${ }^{6}$ The extreme fear of COVID-19 increases stress and adverse emotions in humans, especially in nurses who have to take care of patients. ${ }^{7}$

The nurses who are at the front line of defeating
COVID-19 are considered as high-risk groups of this disease because of having direct contact with patients. The high rate of stress in this occupation has a direct impact on the mental and physical health of nurses. Acceptance and commitment therapy (ACT) is a psychological approach, based on experience, which utilizes strategies that rely on knowledge, commitment, and acceptance to increase psychological flexibility. Hospital healthcare workers (HCWs) endure stress that is beyond their tolerance threshold which may result in burnout. Previous research has demonstrated that nurses are more susceptible to burnout. They are discontent with their job and take any chance to leave their job. ${ }^{8}$ Previous studies on the efficiency of ACT in nurses showed that ACT can improve the living quality and resilience, ${ }^{9}$ moral distress and resilience, ${ }^{10}$ and social and health coping. ${ }^{11}$ Also, ACT has been shown to mitigate stress ${ }^{12}$ and anxiety. ${ }^{13-15}$ According to the high outbreak of COVID-19 and the important role nurses have in preserving the health of patients and society, designing approaches to increase mental health is an essential matter. Prior to the outbreak

(C) 2021 The Author(s). This is an open access article distributed under the terms of the Creative Commons Attribution License (http:// creativecommons.org/licenses/by/4.0/), which permits unrestricted use, distribution, and reproduction in any medium, provided the original work is properly cited. 
of coronavirus, nurses worked normally and routinely, but during the pandemic, there was a lot of stress and anxiety on them, and no one worked on their stress and anxiety. Therefore, considering the lack of studies on evaluating the effectiveness of ACT to improve the mental health of nurses, we aimed to evaluate the effect of ACT on the occupational stress and the anxiety of nurses caring for patients with COVID-19.

\section{Materials and Methods}

This was an experimental study with pre-test post-test design with a control group. The subjects of the study included all the nurses of patients with COVID-19 in a governmental hospital in Tehran during six months of 2020. The hospital was chosen randomly amongst the governmental hospitals of Tehran that offer services to patients with COVID-19. Among the nurses of that hospital who had the inclusion criteria, 30 were chosen and divided by simple random sampling into two equal groups of control and intervention. The inclusion criteria were as follows: consent to participate in the study, no history of psychological disorder, having at least three years of work experience, having a score higher than 15 in the anxiety questionnaire. We excluded nurses who were not willing to participate or those who were infected with COVID-19. The data collection tools were Beck's Anxiety Inventory (BAI) and Steinmetz Occupational Stress Questionnaire. ACT was performed for the intervention group during eight sessions, each lasting for 90 minutes. The control group did not receive any intervention. After the end of the program, individuals from both groups, of control and test, were re-examined.

BAI is a self-report questionnaire used to measure the severity of anxiety in adults. It includes 21 items answered on a four-point scale as follows; 0 (never), 1 (low), 2 (moderate), and 3 (severe). Each item describes one of the symptoms of anxiety that individuals suffering from clinical anxiety or in an anxious state usually experience. Individuals must consider their anxiety in the past weeks and give corresponding scores. Hence, the total score ranges from 0 to 63 . Scores of 0-7 indicate no anxiety, 8-15 low anxiety, 16-25 moderate anxiety, and 26-63 severe anxiety. Beck et $\mathrm{al}^{16}$ have reported an internal consistency of 0.92. Also, Fata et $\mathrm{al}^{17}$ reported a Cronbach's alpha coefficient of 0.86 , internal consistency coefficient of 0.92 , and a reliability coefficient of 0.94 .

Steinmetz Occupational Stress Questionnaire was developed by Steinmenz (1977), and incudes 36 items about stressful situations in the working environment and evaluates the individual's stress regarding the nature of work, colleagues, and supervisors. In the main form, each phrase has five answers (Never, Rarely, Sometimes, Often and Always) scored from 0 to 4 . In the present study, instead of the foretold answers, a three-point scale was used and scored as 0 (completely true), 1 (somehow true), and 2 (not true). Bisection and retest methods were used to determine its reliability yielding a reliability coefficient of 0.69 in the Bisection method and 0.72 in the retest method and also the validity of this test was 0.77 . Table 1 shows the therapy sessions based on ACT which were designed according to the concepts of Omidi and Ardakani. ${ }^{18}$

Data were analyzed using the SPSS software, version 23. Multivariate analysis of variance (MANOVA) was used. It should be noted that before completing the questionnaire, the ethical principles of the study were applied: the individuals were informed about the aims and the methodology of the research, and also that the private and personal information of the individuals were kept safe, and the results were described to them in case of their interest.

\section{Results}

The mead age of the nurses was 39.53 years. 52\% were married, and $48 \%$ were single. Also $68 \%$ of participants had a B.A degree, and $32 \%$ had M.A. degree or higher. Before performing MANOVA, Kolmogorov-Smirnov test was used to check normality. Also, Box's test $(P=0.225)$ showed that the covariance-variance matrices were homogeneous. Levine's test also indicated that the assumption of variance equality was observed. Table 2 shows the average and standard deviation (SD) of pre-test and post-test scores of occupation stress and anxiety in both groups.

As shown in Table 3, there was no significant difference between occupational stress and anxiety scores in control and intervention groups in the pre-test. However, in the post-test, the occupational stress and anxiety scores were significantly lower in the intervention group $(P<0.01)$ compared with the control group. The amounts of ETA square root showed that $66.3 \%$ of the anxiety variance and $51.3 \%$ of the occupational stress variance could be predicted in the posttest through ACT.

\section{Discussion}

We aimed to evaluate the effectiveness of ACT on occupational stress and anxiety in nurses caring for COVID-19 patients. We found that the occupational stress and anxiety scores were significantly lower in the intervention group. Our findings are consistent with several other studies. ${ }^{9-15}$ However, if nurses are more educated and skilled to deal with the stressful situations, the fear associated with COVID-19 can be mitigated. ${ }^{7}$

These findings show that one of the benefits of ACT is teaching individuals to experience their emotions and physical senses without judgement and interference in life. The discrete goal of ACT is to decrease the effort for inner control, and increase behavioral control, and tendency to experience a spectrum of emotions. It could be stated that this method empowers the individual and 
Table 1. Therapy Sessions Based on Acceptance and Commitment Therapy (ACT)

\begin{tabular}{|c|c|c|}
\hline 1- First session & $\begin{array}{l}\text { Making therapy relation } \\
\text { and getting familiar with } \\
\text { group members }\end{array}$ & $\begin{array}{l}\text { Giving information on the } \\
\text { foundation of ACT - } \\
\text { conceptualizing the problem of } \\
\text { participants - preparing the participant and obtaining their informed consent - identifying } \\
\text { goals and needs - } \\
\text { creating motivation for altering and empowering of the participants -Performing pre-test }\end{array}$ \\
\hline 2- Second session & $\begin{array}{l}\text { Describing the } \\
\text { participant's program } \\
\text { and their efficiency }\end{array}$ & $\begin{array}{l}\text { Creating desperation regarding the temporariness and lack of affectivity of therapies using } \\
\text { examples - in this stage, we evaluate the answer to these questions: what efforts has } \\
\text { the visitor done so far? - have the efforts been effective? - these questions are asked to } \\
\text { familiarize the participant with creative desperation - Receiving reaction and presenting } \\
\text { assignments }\end{array}$ \\
\hline 3- Third session & $\begin{array}{l}\text { Helping the visitor in } \\
\text { order to } \\
\text { control personal } \\
\text { happenings }\end{array}$ & $\begin{array}{l}\text { Helping the participant to control personal events, } \\
\text { thoughts, memories and determining ineffective coping strategies and recognizing their } \\
\text { ineffectiveness, accepting harmful personal events without struggling with them and not } \\
\text { controlling them using examples - receiving reaction and presenting assignments }\end{array}$ \\
\hline 4- Fourth session & $\begin{array}{l}\text { Explaining about } \\
\text { evading harmful } \\
\text { experiences }\end{array}$ & $\begin{array}{l}\text { Explaining evading harmful experiences and acknowledging their consequences - } \\
\text { discovering } \\
\text { evaded situations and contact with them through acceptance - we teach the participant } \\
\text { that acceptance is not giving in, but instead of avoiding negative thoughts, the participant } \\
\text { could just acknowledge their presence without reacting - receiving } \\
\text { reaction and presenting assignment }\end{array}$ \\
\hline 5- Fifth session & $\begin{array}{l}\text { Teaching acceptance } \\
\text { steps with } \\
\text { explaining the } \\
\text { excitement concepts and } \\
\text { barriers }\end{array}$ & $\begin{array}{l}\text { Explaining the concept of description and evaluation using examples - altering the } \\
\text { concepts of language using examples - cognitive separation is a method that the visitor } \\
\text { could act independent of these experiences - teaching body relaxation -receiving } \\
\text { reaction and presenting assignments }\end{array}$ \\
\hline 6- Sixth session & $\begin{array}{l}\text { Explaining the concept } \\
\text { of role and background } \\
\text { - creating the self- } \\
\text { observation }\end{array}$ & $\begin{array}{l}\text { Self as background - creating self-observation - teaching the substitution of real self } \\
\text { instead of conceptualized self - acknowledging different sensual receival and separation } \\
\text { from senses which are included as mental content. The participant learns to acknowledge } \\
\text { his/her senses and feelings but not to attach to its content - receiving reaction and } \\
\text { presenting assignments }\end{array}$ \\
\hline 7- Seventh session & Clarifying visitor's values & $\begin{array}{l}\text { Explaining the concept of values and stating the differences among values - in fact, values } \\
\text { are descriptions of what is important for the participant and also the path the participant } \\
\text { wants to move towards the values -receiving reaction and presenting assignments }\end{array}$ \\
\hline 8- Eighth session & $\begin{array}{l}\text { Teaching the } \\
\text { commitment to } \\
\text { perform }\end{array}$ & $\begin{array}{l}\text { Creating commitment for taking } \\
\text { action - reviewing the assignments and concluding the sessions alongside the participant } \\
\text { - performing the post-test }\end{array}$ \\
\hline
\end{tabular}

Table 2. Mean and Standard Deviation (SD) of Pre-test and Post-test Scores of Occupation Stress and Anxiety

\begin{tabular}{llllc}
\hline & & \multicolumn{2}{c}{ Control Group } & \multicolumn{2}{c}{ Intervention Group } & \multicolumn{2}{c}{ Mean } \\
\cline { 3 - 5 } & & Mean & SD & 3.770 \\
\hline \multirow{2}{*}{ Anxiety } & Pre-test & 20.47 & 3.925 & 19.93 \\
& Post-test & 20.53 & 3.292 & 15.60 \\
Occupational & Pre-test & 73.87 & 8.008 & 77.00 \\
stress & Post-test & 73.33 & 8.853 & 58.47 \\
\hline
\end{tabular}

Table 3. Multivariate Analysis of Post-test Variance of Anxiety and Stress Scores

\begin{tabular}{|c|c|c|c|c|c|c|}
\hline \multirow{2}{*}{$\begin{array}{l}\text { Dependent } \\
\text { Variable }\end{array}$} & Square root & \multirow{2}{*}{ DF } & Square Root & \multirow{2}{*}{$\mathbf{F}$} & \multirow{2}{*}{$P$ value } & ATA \\
\hline & Accumulation & & Mean & & & Square Root \\
\hline Anxiety & 153.235 & 1 & 153.235 & 51.135 & $<0.001$ & 0.663 \\
\hline Occupational stress & 2043.960 & 1 & 2043.960 & 27.403 & $<0.001$ & 0.513 \\
\hline
\end{tabular}

facilitates feeling lively. During sessions, individuals learn to accept their feelings instead of walking away from them. Also, their thoughts and the cognitive process will be reached through more mental acknowledgement. They will be led towards goal-oriented activities, and the individuals are asked to work towards their goals and 
values and experience their thoughts and emotions. ${ }^{19}$ The participants also strengthen their psychological flexibility. They develop the ability to feel each and every second of life and alter their behavior in line with their personal values and relevant to the situation. ACT aids individuals in having a more rewarding life even with unpleasant thoughts, excitements, and feelings. The effectiveness of the therapy is related to combining acceptance with mindfulness and commitment. In ACT, when professional difficulties cannot be solved and the employee has no real influence on them, the individual experiences the stress of starting work. The first action an individual needs to take is accepting the stress and anxiety. However, he does not want the same stress and anxiety to take over his life. During the outbreak of the COVID-19, HCWs not only have to work for prolonged hours, but also deal with the stress and anxiety induced by unpredicted emergency conditions. Moreover, the constant wearing of personal protection equipment induces physical exhaustion and psychological pressures. ${ }^{20}$ Overall, the spread of an epidemic creates a general atmosphere of uncertainty that calls for further psychological research to recognize the potential detrimental impacts on the mental health and effectiveness of individuals by systematic scientific activity, to minimize those effects on HCWs. Currently, we empower them against the disease by offering appropriate assistance in terms of understanding their situations and proposing remedies, improving their consciousness, supporting them, and realizing their significance.

\section{Relevance for Clinical Practice}

In a pandemic situation the concern for the medical personnel is an indisputable necessity. Nurses are at the front line of defeating COVID-19, therefore we have to increase their psychological health to ensure the quality of care for patients. ACT gives us such an opportunity. This study should be of interest to readers in the areas of medicine, psychology, and other social disciplines, both for scientists, and practitioners, nurses, and other healthcare providers.

\section{Limitations}

During the COVID-19 outbreak in Iran, our study was undertaken while knowledge of the virus was minimal and information was rapidly evolving. Generalizing the findings should be made with caution since this was a single center study in one hospital. Other research limitations, can be the lack of control of other variables including age, level of education, personality and working background of nurses which could be effective in the results and it is recommended to be controlled in future studies.

\section{Recommendations}

Since media coverage may be emotionally upsetting, news related to COVID-19 has to be reviewed and constrained. The impact of COVID-19 can also be measured by researchers on other disadvantaged populations, including seniors, children and teens, populations living in rural areas with limited access to health services, and people living in countries with lower socio-economic status. It is also essential to design mental health interventions which are culture-sensitive and time-limited, and teachable to volunteers and healthcare workers.

Furthermore, we suggest to hold educational workshops on ACT for nurses to decrease their occupational stress and anxiety and improve their overall well-being and mental health.

\section{Authors' Contribution}

H.M conceived the study, designed the framework and searched for data, A.B prepared the manuscript, B.P gathered the data, and all authors read and approved the manuscript.

\section{Conflict of Interest Disclosures}

The authors declare that they have no conflict of interests.

\section{Ethical statement}

The study has been approved by the Ethics Committee of Shahid Beheshti University of Medical Sciences, Tehran, Iran (Number: IR.SBMU.RETECH.REC.1399.1337).

\section{Funding/Support}

This study did not receive any grant or funding from any private or academic research center.

\section{Acknowledgments}

The research team appreciates the nurses of governmental hospitals in Tehran, who completed the questionnaire and helped us in conducting this research.

\section{References:}

1. Catton H. Global challenges in health and health care for nurses and midwives everywhere. Int Nurs Rev. 2020;67(1):4-6. doi: 10.1111/inr.12578.

2. Farnoosh G, Alishiri G, Hosseini Zijoud SR, Dorostkar $\mathrm{R}$, Jalali Farahani A. Understanding the severe acute respiratory syndrome coronavirus 2 (SARS-CoV-2) and coronavirus disease (COVID-19) based on available evidence - a narrative review. J Mil Med. 2020;22(1):1-11. doi: 10.30491/jmm.22.1.1. [Persian].

3. Wu F, Zhao S, Yu B, Chen YM, Wang W, Song ZG, et al. A new coronavirus associated with human respiratory disease in China. Nature. 2020;579(7798):265-9. doi: 10.1038/s41586-020-2008-3.

4. Talaee N, Varahram M, Jamaati H, Salimi A, Attarchi M, Kazempour Dizaji M, et al. Stress and burnout in health care workers during COVID-19 pandemic: validation of a questionnaire. Z Gesundh Wiss. 2020:1-6. doi: 10.1007/ s10389-020-01313-z.

5. Reith TP. Burnout in United States healthcare professionals: a narrative review. Cureus. 2018;10(12):e3681. doi: 10.7759/ cureus.3681. 
6. Hsiao SJ, Tseng HT. The impact of the moderating effect of psychological health status on nurse healthcare management information system usage intention. Healthcare (Basel). 2020;8(1). doi: 10.3390/healthcare8010028.

7. Mubarak N, Safdar S, Faiz S, Khan J, Jaafar M. Impact of public health education on undue fear of COVID-19 among nurses: the mediating role of psychological capital. Int J Ment Health Nurs. 2021;30(2):544-52. doi: 10.1111/ inm.12819.

8. Dyrbye LN, Shanafelt TD, Johnson PO, Johnson LA, Satele D, West CP. A cross-sectional study exploring the relationship between burnout, absenteeism, and job performance among American nurses. BMC Nurs. 2019;18:57. doi: 10.1186/s12912-019-0382-7.

9. Razmpush M, Ramezani K, Maredpour A, Koulivand PH. The effect of acceptance and commitment training on quality of life and resilience of nurses. Shefaye Khatam. 2019;7(1):62-51. doi: 10.29252/shefa.7.1.62. [Persian].

10. KhanjaniS, Donyavi V, Asmari Y, Rajabi M. The effectiveness of group training acceptance and commitment therapy on moral distress and resiliency in nurses. Journal of Nurse and Physician Within War. 2017;5(16):50-8. [Persian].

11. Noori L, Moradi Shakib A, Ezazi Bojnourdi E, Adib F, Ashoori J. Effectiveness of group therapy based on acceptance and commitment on social and health adjustment of nursing students. Avicenna J Nurs Midwifery Care. 2018;25(5):172-9. doi: 10.30699/sjhnmf.26.5.3. [Persian].

12. Brown FL, Whittingham K, Boyd RN, McKinlay L, Sofronoff K. Does Stepping Stones Triple P plus Acceptance and Commitment Therapy improve parent, couple, and family adjustment following paediatric acquired brain injury? a randomised controlled trial. Behav Res Ther. 2015;73:58-66. doi: 10.1016/j.brat.2015.07.001.

13. Ivanova E, Lindner P, Ly KH, Dahlin M, Vernmark K, Andersson G, et al. Guided and unguided Acceptance and Commitment Therapy for social anxiety disorder and/or panic disorder provided via the Internet and a smartphone application: a randomized controlled trial. J Anxiety Disord. 2016;44:27-35. doi: 10.1016/j.janxdis.2016.09.012.

14. Fledderus M, Bohlmeijer ET, Fox JP, Schreurs KM, Spinhoven P. The role of psychological flexibility in a selfhelp acceptance and commitment therapy intervention for psychological distress in a randomized controlled trial. Behav Res Ther. 2013;51(3):142-51. doi: 10.1016/j. brat.2012.11.007.

15. McCracken LM, Gutiérrez-Martínez O. Processes of change in psychological flexibility in an interdisciplinary groupbased treatment for chronic pain based on Acceptance and Commitment Therapy. Behav Res Ther. 2011;49(4):267-74. doi: 10.1016/j.brat.2011.02.004.

16. Beck AT, Steer RA, Garbin MC. Psychometric Properties of the Beck Depression Inventory. Twenty-Five Years of Evaluation. Clinical Psychology Review. 1988; 8: 77-100. doi: 10.1016/0272-7358(88)90050-5

17. Fata L, Birashk B, Atefvahid MK, Dabson KS. Meaning assignment structures/ schema, emotional states and cognitive processing of emotional information: comparing two conceptual frameworks. Iran J Psychiatry Clin Psychol. 2005;11(3):312-26. [Persian].

18. Omidi A, Ardakani SQ. Treatment based on admission and commitment in anxiety. Kashan University of Medical Sciences and Health Services. 2016:Presentations 38-9. [Persian]. Available from: http://opac.nlai.ir/opac-prod/ bibliographic/4240599

19. Tabatabaii, Sadat A, Sajjadian I, Motamedi M. Effectiveness of therapy based on acceptance and commitment on sexual performance, sexual shyness and sexual encouragement of women suffering from sexual disorders. Behavioral Sciences Studies. 2017;15(1):84-92. [Persian].

20. Al-Rabiaah A, Temsah MH, Al-Eyadhy AA, Hasan GM, Al-Zamil F, Al-Subaie S, et al. Middle East respiratory syndrome-corona virus (MERS-CoV) associated stress among medical students at a university teaching hospital in Saudi Arabia. J Infect Public Health. 2020;13(5):687-91. doi: 10.1016/j.jiph.2020.01.005. 